

\title{
Despesas com gestão ambiental nos estados da Amazônia Legal
}

\section{Expenditure on environmental management in the states of Legal Amazon}

\author{
Elenize Freitas Avelino* | Alexandre Almir Ferreira Rivas** | \\ Roberta Monique da Silva Santos*** | Orleylson Cunha Gomes**** \\ http://dx.doi.org/10.51861/ded.dmvu.2.011 \\ Recebido em 13 de fevereiro de 2020. Aceito em 28 de julho de 2020.
}

\begin{abstract}
Resumo
Os governos, mediante legislações específicas, preveem e destinam recursos financeiros para a gestão ambiental. Considerando isto e a necessidade de verificar como esse recurso é alocado, o presente artigo teve por objetivo analisar o comportamento das despesas com gestão ambiental no orçamento dos estados da Amazônia Legal entre os anos de 2005 a 2015, identificando como cada estado designou e aplicou recursos para a gestão ambiental dentre as suas subfunções. Utilizou-se pesquisa documental-descritiva, de cunho quantitativo; e dados de despesas totais e de despesas com gestão ambiental, na forma de despesa liquidada, extraídas do site do Tesouro Nacional. Os estados do Mato Grosso, Pará, Amazonas e Acre são os que mais destinaram recursos para a área ambiental. Quanto à participação da despesa com gestão ambiental nos orçamentos governamentais, observou-se que a gestão ambiental correspondeu a menos de $1 \%$ dos orçamentos dos estados da Amazônia Legal no período analisado.
\end{abstract}

Palavras-chave: Despesas Governamentais, Despesas com Gestão Ambiental, Amazônia Legal.

\begin{abstract}
Governments, through specific legislation, provide and allocate financial resources for environmental management. Considering this and the need to verify how this resource is allocated; this article aimed to analyze the behavior of environmental management expenses in the budget of the states of Legal Amazon between the years 2005 to 2015; identifying how much each state designated for environmental management among its sub-functions. Documentary-descriptive research was used, of a quantitative nature and data on total expenses and expenses on environmental management, in the form of paid expenses, were extracted from the National Treasury website. The states of Mato Grosso, Pará, Amazonas and Acre are the ones that most allocated resources to the environmental area. Regarding the share of expenditure on environmental management in government budgets, it was observed that environmental management corresponded to less than $1 \%$ of the budgets of the states of the Legal Amazon in the analyzed period.
\end{abstract}

Keyword: Government expenditure, Expenditure on environmental management, Legal Amazon.

\footnotetext{
* Elenize Freitas Avelino. Mestre em Ciências Ambientais e Sustentabilidade na Amazônia pela UFAM. Av. Rio Negro, 189 - Santo Agostinho, Manaus- AM, CEP: 69.036-720.

ORCID: 0000-0003-1740-6931 (https://orcid.org/0000-0003-1740-6931). E-mail: elenavelino36@gmail.com.

** Alexandre Almir Ferreira Rivas Professor da Universidade Federal do Amazonas. Av. Gal. Rodrigo Otávio Jordão Ramos, 3000 - Campus Universitário UFAM / Manaus, AM , 69077-000.

ORCID: https://orcid.org/0000-0003-1794-8909. E-mail: central.rivas@gmail.com

*** Roberta Monique da Silva Santos - Professora da Faculdade Salesiana Dom Bosco. AV. Cosme Ferreira, 5122 Zumbi dos Palmaires, Manaus- AM, CEP: 69084-425.

ORCID: https://orcid.org/0000-0002-7624-4824.E-mail: robertamonicke@gmail.com

**** Orleylson Cunha Gomes - Profesor, Secretaria Municipal de Educação. Av. Mário Ypiranga, 2549 - Parque Dez de Novembro, Manaus - AM, CEP: 69055-010.

ORCID: https://orcid.org/0000-0001-7066-6113. E-mail: orleylson.gomes@semed.manaus.am.gov.br.
} 


\section{INTRODUÇÃO}

O surgimento das preocupaçôes com o meio ambiente se intensificou no fim da década de 1960. A atenção que passou a ser dada as questóes ambientais ganhou mais destaque com a publicação feita pelo Clube de Roma e o relatório "Os limites do crescimento" (1972), aliada a incidência de acidentes ambientais ocorridos em diversos países. A partir desse momento os governos, motivados por pressóes internacionais oriundas de conferências que abordavam o possível problema ambiental, causado pelas açóes humanas, passaram a inserir em suas responsabilidades a preservação dos recursos naturais (BARATA et al, 2007).

No Brasil, o artigo 225 da Constituição Federal de 1988, define que é dever do Estado oferecer um ambiente ecologicamente equilibrado a população. Para isso, ele se utiliza de políticas públicas ambientais que são viabilizadas mediante a verba presente no orçamento governamental, na forma da Despesa por função Gestão Ambiental.

Ampliando a discussão, que balizará este artigo, despesa orçamentária pública é entendida como aquela que é executada por entidade pública, mediante ato autorizativo para sua realização e que consiste em um conjunto de gastos associados a implementação e manutenção de serviços públicos (MINISTÉRIO DA ECONOMIA, 2020).

Segundo a Interpretação Técnica Geral de número 2004, do Conselho Federal de Contabilidade, Despesa ambiental pode ser entendida, também, como o gasto em relação com o meio ambiente de forma indireta (CFC, 2013). Esta definição é complementada por Ribeiro (2010) que dispõe que despesas ambientais são gastos envolvidos no gerenciamento ambiental, de forma indireta, como aqueles envolvidos na área administrativa ou ao consumo de recursos que estejam associados a gestão ambiental. Portanto, consideram-se como despesas ambientais os gastos com aquisição, contratação de obras e compras (MMA, 2020). São exemplos de despesas ambientais gastos com: coleta de dados e informações e em trabalhos de campo, gastos com estudos ambientais e monitoramento de impactos (CFC, 2013). A destinação dos recursos para a gestão ambiental possibilita a execução de ações necessárias ao melhor cumprimento das políticas públicas de preservação de recursos naturais, na qual se insere a proteção da Floresta Amazônica (YOUNG, 2005).

No intuito de promover a conservação desta região, no que concerne ao território brasileiro, e propiciar o seu desenvolvimento econômico, o Brasil em seu Decreto 1.806/53 promoveu a criação da Amazônia Legal. Possuindo uma extensão territorial de $5.015 .067,749 \mathrm{~km}^{2}$, essa região é composta pelos estados do Acre, Amapá, Amazonas, Pará, Rondônia, Roraima, Tocantins, 
Mato Grosso e Maranhão; que abrigam a maior parte da floresta em seus territórios (IBGE, 2019).

Considerando a importância dessa região, parte do orçamento público foi destinado a ações e políticas visando sua preservação e conservação ambiental. O orçamento público, que consiste em um instrumento utilizado pelos governos para planejar como utilizar o dinheiro arrecadado em favor dos serviços públicos fornecidos a sociedade, é expresso na forma de receitas estimadas, como também despesas fixadas. A receita consiste no dinheiro obtido pelo governo por meio dos tributos, da venda de bens e de títulos públicos, da prestação de serviços e indenizações. A despesa consiste em um conjunto de gastos efetuados pelo poder público para garantir a manutenção dos serviços a sociedade. Como, no orçamento público, cada gasto é detalhado é possível compreender, por meio dessa especificação, o que é tido como prioridade. Logo, se uma determinada despesa, como por exemplo a educação, recebe recursos constantes e crescentes ela é considerada prioritária.

Para compreender se a gestão ambiental é considerada como prioridade para esses estados é preciso analisar a despesa com gestão ambiental. Nesse sentido, o presente artigo tem por objetivo analisar o comportamento das despesas com gestão ambiental no orçamento dos estados que compóem a Amazônia Legal entre os anos de 2005 a 2015. Mais especificamente, será analisado o quanto cada estado designou para a gestão ambiental e como esse recurso foi aplicado dentre as suas subfunçóes.

Diante disso, o presente artigo está estruturado em três seções: inicialmente é apresentado uma breve conceituação a respeito dos gastos governamentais e dos gastos com gestão ambiental. A segunda seção apresenta os materiais e métodos aplicados nessa pesquisa, e a última seção os resultados obtidos, bem como as suas discussóes.

\section{A QUESTÃO AMBIENTAL E A ATUAÇÃO GOVERNAMENTAL}

\section{Gastos Governamentais}

Os gastos públicos refletem as prioridades do governo, na forma de prestação de serviços básicos e de investimentos executados. Segundo Gremaud (2009), os gastos do governo são os recursos utilizados para que o Estado possa fazer frente aos seus compromissos. Nos quais, há a divisão em despesas correntes, despesas com funcionários, serviços, materiais, e transferências governamentais.

Os gastos governamentais consistem em uma opção estritamente política dos governos para ofertar os serviços a sociedade. Demonstram dispêndio referente a quantidade e qualidade dos serviços por eles prestados. Tais 
gastos estão associados a questões políticas, administrativas e ideológicas, que definem o modo como ocorrerá a destinação de recursos para as mais diversas áreas. Logo, faz-se necessário o monitoramento de como tais recursos vêm sendo aplicados de modo a torná-los cada vez mais eficientes. Esse controle acerca da quantidade e da destinação dos recursos é elaborado por meio do orçamento público (AMARANTE \& MOREIRA, 2009, apud RIANE 1997; BUENO et al.,2013).

$\mathrm{O}$ orçamento consiste em um documento legal utilizado pelos governos para expressar as suas receitas e despesas em um determinado período, denominado de exercício financeiro. O orçamento é um instrumento de controle de gastos que possibilita o gerenciamento de recursos para atividades e projetos. Geralmente ele é expresso em moeda de modo a evidenciar a política econômica adotada (VASCONCELLOS \& GARCIA, 2008, AMARANTE \& MOREIRA, 2009, GRUDTNER \&ARANGO, 2017).

No caso do Brasil, o orçamento é regulamentado por princípios regidos pela Constituição Federal de 1988, na qual, em seu artigo 165, menciona que o orçamento é composto do Plano Plurianual (PPA), pela Lei de Diretrizes Orçamentárias (LDO) e a Lei Orçamentária Anual (LOA) (BRASIL, 1988).

O PPA aborda os objetivos, as diretrizes e as multas adotadas pelo poder público de forma regionalizada, para efetivar despesas de capital e as demais despesas decorrentes, de modo que se possa garantir a perpetuação de programas sociais já estabelecidos. A LDO contempla as açôes prioritárias e aquelas as quais a Administração pública deseja alcançar. Nela, se inserem as despesas de capital, orientaçóes para formular a Lei Orçamentária Anual, as alterações na legislação tributária, além de demonstrar as políticas a serem adotadas por agências de fomento. A LOA é composta pelos orçamentos adotados pela União, seus fundos e órgãos da Administração Direta e Indireta. Ela também contém o orçamento das empresas nas quais a União possui parte do capital social, conferindo a mesma o direito de voto. Além disso, a LOA também compreende o orçamento da seguridade social e dos fundos e fundações mantidos pela Administração Pública (VASCONCELLOS \& GARCIA, 2008).

Em 4 de maio de 2000, foi instituída a Lei de Responsabilidade Fiscal (LRF), que estabelece um conjunto de normas aplicadas às finanças públicas, com o objetivo de propiciar um maior equilíbrio orçamentário ao poder público, tendo como premissas o planejamento, o controle, a transparência e a responsabilidade. Para isso, ela estabelece um limite aos gastos da União, dos Estados e dos Municípios e, também, expressa a proibição de socorro financeiro entre os órgãos da Administração Pública. Além disso, a LRF limita o endividamento destes entes, bem como restringe os gastos feitos 
pelos gestores públicos no fim do seu mandato (BRASIL, 2000; AGENCIA SENADO, 2020).

A instituição destas leis implica em uma maior eficiência e transparência das ações do governo e impulsiona os Estados, Municípios e a União a fazerem uso de seus próprios recursos, colaborando com o ajuste fiscal das contas públicas (ROSA et al, 2018, VASCONCELLOS \& GARCIA, 2008).

Diante disso, diversos autores presentes na literatura fizeram análises acerca de quais despesas tem maior representação no orçamento público. Cota (2017), por exemplo, identificou um crescimento real do gasto primário de $\mathrm{R} \$ 186,2$ bilhóes no período de 2010 a 2015 . Onde $83 \%$ das despesas corresponderam a um aumento de gastos sociais, gastos previdenciários e gastos com transferências de renda às famílias.

Nesse sentido, a análise de trabalhos voltados a composição dos gastos públicos auxilia na compreensão daquilo que é tido como prioridade para os governos. Assim, pesquisas voltadas a análise dos gastos públicos são relevantes tanto para a sociedade civil como para os administradores públicos. Aos primeiros, a importância está atrelada ao acesso as informações acerca da aplicação dos recursos públicos, dessa forma as pessoas podem entender onde seus tributos estão sendo destinados e avaliar a eficácia desse investimento por parte dos gestores públicos. Quanto aos administradores públicos, observa-se uma maior preocupação na alocação dos recursos tendo em vista a transparência que os mesmos devem apresentar frente a população (BUENO; OLIVEIRA \& BORINELLI, 2013; COTA, 2017).

\section{Despesas com gestão ambiental}

A preocupação em elaborar políticas públicas em função do meio ambiente surgiu no Brasil a partir da década de 1970, sendo impulsionada por pressóes sociais, oriundas da poluição das indústrias, da perda de biodiversidade e, também de conferências internacionais voltadas para os efeitos dos problemas relacionados ao meio ambiente. Diante desse cenário, o governo deparou-se com a necessidade de adotar medidas para mitigar os impactos ambientais decorrentes das atividades econômicas. Tais medidas configuraram-se essencialmente em políticas públicas ambientais (BESKOW $\&$ MATTEI, 2012).

A política pública ambiental é definida por Lima (2011, apud BARBIERI, 2006, p.122) como "um conjunto de diretrizes, objetivos e instrumentos de ação que o poder público se utiliza para produzir efeitos desejáveis ao meio ambiente”. Já Hayashi e Silva $(2015$, p. 3) afirmam que tais políticas devem "ser orientadas na resolução de conflitos sociais, ambientais, visando principalmente o bem-estar social e a conservação dos recursos naturais”. 
O financiamento dessas políticas é realizado pelo governo, que se utiliza de seus recursos públicos para subsidiar a preservação do meio ambiente, por meio da alocação dos recursos na modalidade despesa pública.

Gasto público é entendido como o desembolso financeiro realizado pelo estado em prol de interesses da coletividade (BAQUERO et al, 2006), já os gastos públicos ambientais, segundo Guandalini et al (2013) são aqueles feitos especificamente neste setor. Entender como estes gastos são distribuídos e efetivamente executados, contribui para uma gestão mais eficiente dos recursos públicos.

A Portaria número 42 de 14 de abril de 1999 classificou as despesas públicas por função e subfunção, permitindo identificar e agrupar os gastos públicos por área de ação governamental. Como função entende-se "o maior nível de agregação das diversas áreas de despesa que competem ao setor público" e esta, reflete a competência institucional do órgão; e como subfunção, compreende-se como um subconjunto de despesa do setor público”, ou seja, corresponde a uma parte da função e evidencia a natureza da atuação governamental (BRASIL, 2017).

$\mathrm{Na}$ referida portaria são elencadas 28 funçóes, cada uma com suas respectivas subfunções, dentre elas está a função Gestão Ambiental, de número 18, a qual abrange cinco subfunções: preservação e conservação ambiental, controle ambiental, recuperação de áreas degradadas, recursos hídricos e meteorologia.

A função Gestão Ambiental abrange o conjunto de ações desenvolvidas para a proteção, monitoramento, controle e recuperação ambiental. A subfunção Preservação e Conservação Ambiental abrange ações voltadas à preservação e conservação ambiental, da fauna e flora, em seus mais diversos ecossistemas, seja em áreas urbanas ou rurais. A subfunção Controle Ambiental está voltada a açóes direcionadas ao controle da poluição e impactos ao ambiente. A subfunção Recuperação de áreas degradadas refere-se ao conjunto de ações voltadas a recuperação de áreas que foram impactadas pela ação humana. Quanto a Subfunção Recursos Hídricos, entende-se como um conjunto de ações que possam promover o aproveitamento ambientalmente responsável dos corpos hídricos para fins de abastecimento das atividades humanas e por fim, a subfunção Meteorologia, que compreende ações voltadas para o estudo e monitoramento das condições meteorológicas e climáticas (MOURA et al, 2017; TCU, 2014).

A despesa gestão ambiental configura-se como uma despesa pública essencial, exigindo constantes e crescentes aplicações de recursos financeiros. O estudo da relevância da aplicação destes recursos para a gestão ambiental, apesar de recente, já foi objeto de estudo de diversos autores (GALINATO \& 
GALINATO, 2016, ALMEIDA; GIAMBIAGI \& PESSOA, 2008, BUENO; OLIANA \& BORINELLI, 2013).

Rosa et al (2017) analisaram a evolução dos gastos com gestão ambiental nas épocas de enchente e pós enchente, em Santa Catarina, no período de 2008-2014. O trabalho constatou que a gestão ambiental apresenta baixa prioridade na região, através do baixo valor destinado a esta despesa ou até mesmo na inexistência de recursos para ela. Além disso, observou-se que quando os recursos eram aplicados havia a concentração dos mesmos na subfunção Controle ambiental de modo que se mantivesse apenas a fiscalização dos recursos naturais.

Guandalini et al (2013) analisaram quantitativamente os gastos públicos ambientais no período de 2002-2010. Seus resultados demonstraram a diminuição de recursos públicos para a área ambiental. Observou-se que a administração pública das capitais deu pouca prioridade a área ambiental, onde os maiores montantes de recursos encontram-se nas regióes sul e sudeste. $\mathrm{O}$ padrão de distribuição da função gestão ambiental não é equilibrado, privilegiando-se as subfunçóes conservação e preservação ambiental e outras despesas.

Reis e Oliana (2014) mensuraram o comportamento dos gastos públicos na cidade de Londrina, no período de 2002-2011. Eles constataram que a cada $\mathrm{R} \$ 1.000,00$ gastos, pouco mais de $\mathrm{R} \$ 25$ é destinado a área ambiental. O que implica em índices considerados satisfatórios no que concerne a aplicação de recursos para a gestão ambiental, evoluindo em cerca de 2,56\% no período citado. Quando se analisou onde se concentrou a aplicação destes gastos na despesa gestão ambiental observou-se a predominância de recursos para urbanização, limpeza pública, correta destinação de resíduos e manutenção de parques e praças.

Dantas et al (2014) analisaram os gastos públicos com a função gestão ambiental no orçamento brasileiro para o período de 2004-2011, comparando o seu desempenho ao da China e U.E. Os autores constataram que as despesas ambientais não possuem tanta prioridade no orçamento, correspondendo a valores de $1 \%$ no orçamento.

Nesse sentido, foi possível observar a relevância do estudo dos gastos públicos ambientais sob diversos aspectos, constatando-se a existência de variaçốes no montante destinado a gestão ambiental ocasionadas por fatores econômicos e políticos. Dantas et al (2014) afirma que cabe a cada país definir sua política ambiental, baseando-se nas suas características do meio físico, escalas de atuação, urbanização e nas questôes sociais. 


\section{MATERIAIS E MÉTODOS}

O presente estudo consiste em uma pesquisa documental-descritiva, de cunho quantitativo. Este tipo de pesquisa baseia-se na análise de dados que ainda não passaram por investigaçóes, usando para isso procedimentos de estatística descritiva; isso se deve aos altos números de amostras, o que permitem que seus resultados sejam quantificáveis e gerem discussóes posteriores. Por conta disso esse tipo de pesquisa tem como foco a objetividade (GERHARDT \& SILVEIRA, 2009).

Utilizou-se pesquisa bibliográfica em artigos científicos cuja busca se deu com as palavras chaves: gastos, despesas e meio ambiente em revistas especializadas em sites de hospedagem. A pesquisa bibliográfica aborda uma gama de publicações de periódicos sobre determinado tema possibilitando ao pesquisador ter uma visão abrangente, permitindo assim a sua seleção posterior.

Esse trabalho utilizou o procedimento documental, em documentos governamentais, entendido como aquele que permite o acesso a diversas fontes dispersas sem o devido tratamento analítico, nas quais se inserem jornais, revistas, relatórios, além de tabelas estatísticas. Podendo essas fontes serem classificadas em fontes primárias, como é o caso das estatísticas sob a forma de censo, e fontes secundárias, sendo os relatórios oficiais um exemplo deste tipo de fonte. Sendo extraídas de arquivos públicos na forma de documentos oficiais, publicações parlamentos e pareceres jurídicos (LAKATOS, 2003).

\section{Fonte de dados}

Os dados nos quais a pesquisa se baseou foram as despesas totais e as despesas com gestão ambiental, na forma de despesa liquidada, extraídas do site do Tesouro Nacional (STN) ${ }^{1}$. Os valores referentes a essas despesas foram atualizados com base no Índice de Preços ao Consumidor Amplo (IPCA) de 2014, de modo a eliminar o efeito da inflação do período.

O Tesouro Nacional fornece dados consolidados referentes a administração orçamentária e financeira por meio do Sistema de Informações Contábeis e Fiscais do Setor Público Brasileiro (SICONFI). Esse sistema consiste em uma ferramenta de obtenção e análise de informações contábeis, financeiras e de estatísticas fiscais utilizada por todos os poderes e órgãos de 5.638 municípios, 26 Estados, Distrito Federal e União. Oferece uma série de informações na forma de dados orçamentários e relatórios disponibilizados através de uma plataforma constituída de duas interfaces: a área privada e a pública (SICONFI, 2018).

Através da Execução Orçamentária e Financeira é possível ter acesso a dotação orçamentaria e a execução das despesas autorizadas com pessoal e 
encargos, com despesas de custeio e capital, disponíveis por órgão, função, projeto e atividade. Estes dados são fornecidos a preços correntes, em outras palavras, ao preço do ano vigente (MINISTÉRIO DA ECONOMIA, 2020).

Para compreender se a gestão ambiental é considerada uma prioridade, em termos de alocação de recursos públicos, para os estados que compóem a Amazônia Legal, foram coletados dados dos gastos governamentais desses estados para o período de 2005 a 2015. É preciso salientar que o estado do Maranhão, pertencente a região nordeste do país, possui uma área de $25 \%$ da Amazônia Brasileira em seu territórioº ${ }^{2}$ que está incluída na definição sobre a Amazônia legal.

Desta forma, dados sobre os gastos governamentais com gestão ambiental deste estado, também foram inseridos na análise, pois como parte da Amazônia se assenta em seu território, a sua inclusão é pertinente visto a sua expressiva significância para o cuidado e preservação da floresta. Assim, será possível verificar se esse fato influencia ou não a importância atribuída a gestão ambiental no orçamento do Maranhão.

\section{RESULTADOS E DISCUSSÕES}

A maneira dos estados despenderem recursos na despesa com gestão ambiental diverge entre as regiôes brasileiras. $\mathrm{O}$ nível de gasto nessa área pode estar associado a diversos fatores, dentre os quais se destaca a riqueza econômica, a severidade dos problemas ambientais e o índice de desenvolvimento humano da região (IDESAM, 2017; BORINELLI et al, 2017).

A despesa com gestão ambiental passou a constar nos relatórios da execução orçamentária a partir de 2002. De acordo com a figura 1 é possível observar o crescimento, mesmo que em certos casos, de forma incipiente, das despesas com gestão ambiental dos estados que compõe a Amazônia Legal. Foi possível verificar que no período de 2005 a 2015 as despesas apresentaram um crescimento de $95 \%$. A evolução temporal desta despesa por estado pode ser observada na figura 1 .

Os estados do Mato Grosso, Amazonas, Pará e Acre são os que mais gastam na despesa por função gestão ambiental no acumulado de 10 anos. Nesse período, as despesas com gastos no setor ambiental apresentaram uma tendência crescente nos estados de Roraima, Tocantins, Maranhão, Rondônia, Acre, Pará e Mato Grosso. O estado do Amapá, apresenta estabilidade e leve baixa nesses gastos e o Amazonas, que inicialmente era um dos maiores em relação aos gastos com a questão ambiental, apresentou uma queda nos valores destinados a essas despesas a partir de 2014. 
Figura 1 - Despesa com gestão ambiental por Estado

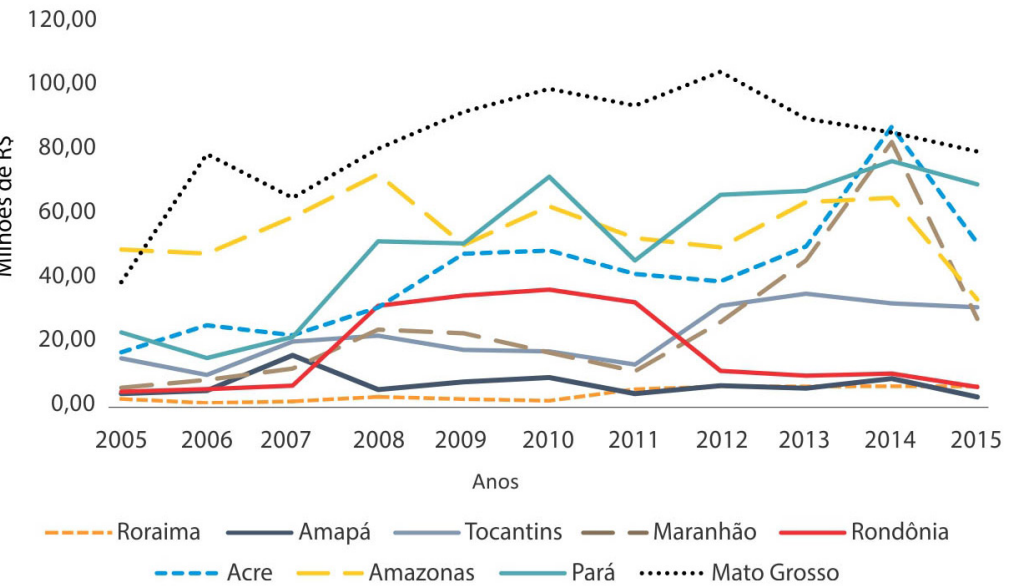

Fonte: Elaborado pelos autores, com base nos dados do STN, 2019.

O comportamento das despesas bem como a diferenciação de recursos orçamentários entre os estados pode ser explicado pelos acontecimentos políticos e econômicos vivenciados no período, como a posse do novo governador do Estado e a redução significativa de investimentos para o combate ao desmatamento do governo federal. Guandalini et al (2013) e Rosa et al (2018) apontam que o setor ambiental ainda está se consolidando. Logo, ele sofre restrições políticas e econômicas, o que tem relação direta com as políticas ambientais adotadas e a eficácia das mesmas (LEMOS et al, 2005).

$\mathrm{Na}$ série analisada é possível observar um aumento do valor destinado a essa despesa até 2010 como reflexo da maior destinação de recursos públicos para se controlar as elevadas taxas de desmatamento destas regióes; além da necessidade de se controlar a degradação ambiental ocasionada por fatores políticos e econômicos predominantes em cada estado. A partir de 2010 observa-se uma queda nessa despesa em todos os estados, o que pode ser associado como um dos resultados dos efeitos da crise econômica e financeira internacional vivenciada em 2008.

A literatura aponta que a crise americana influenciou a economia de todos os países, no entanto seus efeitos em cada país divergiram uns dos outros. No caso do Brasil, os efeitos da crise foram sentidos com mais intensidade após 2010, fato este que pode ser observado por meio da queda nas despesas nos anos de 2011 e 2012. No entanto, a política implementada pelo governo brasileiro teve êxito de modo que o país não sofreu os impactos da crise da mesma forma que os EUA e alguns países europeus. Buscou-se esti- 
mular a economia interna, reduzir impostos sobre produtos industrializados e outros incentivos econômicos (FERRAZ, 2013; LIMA \& DEUS, 2013). Gerou-se assim, uma pressão maior sobre os recursos naturais, ao passo de que aumentou a pressão para redução do controle ambiental das atividades econômicas (JUNIOR, 2016).

Porém, essa busca por recursos gerou débitos consideráveis e significativos às florestas da Amazônia, pois de acordo com o INPE (2009), 12.911 quilômetros quadrados foram ilegalmente desmatados na Amazônia legal, principalmente em áreas de preservação permanente, como as margens de rios, abrigo de espécies ameaçadas de extinção e áreas de declive acentuado. Isso colocou um alerta em relação ao desmatamento, pois este número significa uma reversão de um período de três anos consecutivos de queda no desmatamento que levou a uma redução acumulada de $58 \%$ na sua taxa entre 2004 e 2007.

No entanto, os gastos realizados pelo governo demonstram que o ano de 2008 foi o que mais se investiu em medidas de combate ao desmatamento, segundo dados do PRODES (2009). No extrato por estado, no Amazonas foram gastos R\$71.835.782,00. Além disso, houve a criação do Fundo Amazônia, que tem por finalidade captar doaçôes para investimentos não reembolsáveis em ações de prevenção, monitoramento e combate ao desmatamento e de promoção da conservação e do uso sustentável da Amazônia Legal.

Ainda assim é possível constatar uma queda nas despesas em 2015 em virtude da situação econômica vivenciada e da crise da democracia que se iniciou em 2013, com as manifestaçóes populares culminado no impeachment da então presidente Dilma Roussef.

Essa queda nos gastos com a preservação da floresta, segundo Rosa (2015), são referentes aos investimentos no PPCDAm - Plano para Controle do Desmatamento Ilegal e Recuperação da Vegetação Nativa - que é estruturado em três eixos com orçamentos independentes: ordenamento fundiário e territorial, monitoramento e controle ambiental e fomento às atividades produtivas sustentáveis (MMA, 2020). A partir da análise de tal programa, bem como dos dados obtidos neste estudo, verifica-se que houve uma queda acentuada nos gastos nas medidas de combate ao desmatamento entre o segundo governo do Presidente Luís Inácio Lula da Silva e o primeiro da Presidente Dilma Rousseff. O total de gastos com PPCDAm no segundo mandato Lula (2007-2010) foi R \$ 6,4 bilhóes, enquanto que no primeiro mandato de Dilma (2011-2014) foi de apenas 1,8 bilhão.

Além disso, a crise política teve relação direta com a economia do país o que implicou na redução de sua arrecadação e, consequentemente, na destinação de menores recursos para o fornecimento de serviços públicos, dentre 
os quais se insere a gestão ambiental. Esse resultado corrobora com aqueles apontados pela literatura, nos quais se afirma que a Despesa com Gestão Ambiental é explicada por fatores políticos, econômicos e ideológicos de cada região (LEMOS, YOUNG \& GELUDA, 2005; BUENO, OLIANA \& BORINELLI, 2014; GALASSI et al, 2017, ZHANG, 2017).

Para compreender como foram distribuídos os recursos destinados a despesa com gestão ambiental e assim entender o que é de fato prioridade para os estados, em termos de alocação de recursos, é preciso analisar as suas subfunçóes. A tabela 1 demonstra como os estados alocam seus recursos entre as subfunções.

Tabela 1 - Dispêndio médio por subfunção no período de 2005 a 2015

\begin{tabular}{|c|c|c|c|c|c|c|}
\hline Estado & $\begin{array}{c}\text { Preservação e } \\
\text { Conservação } \\
\text { Ambiental }\end{array}$ & $\begin{array}{l}\text { Controle } \\
\text { Ambiental }\end{array}$ & $\begin{array}{l}\text { Recursos } \\
\text { Hídricos }\end{array}$ & $\begin{array}{c}\text { Recuperação } \\
\text { de áreas } \\
\text { degradadas }\end{array}$ & Meteorologia & $\begin{array}{c}\text { Demais } \\
\text { Subfunções } \\
\text { - Gestão } \\
\text { Ambiental }\end{array}$ \\
\hline $\mathrm{RR}$ & $1.544 .876,26$ & $1.143 .581,28$ & $487.255,82$ & 0,00 & 0,00 & $2.922 .258,64$ \\
\hline AP & $3.403 .496,59$ & $450.437,96$ & $27.543,83$ & 0,00 & 0,00 & $10.599 .627,45$ \\
\hline TO & $8.930 .679,31$ & $2.476 .283,70$ & $1.503 .256,85$ & $91.217,35$ & 0,00 & $8.593 .369,01$ \\
\hline MA & $15.700 .034,91$ & $448.781,05$ & $301.764,22$ & 0,00 & 0,00 & $8.548 .242,55$ \\
\hline RO & $6.055 .175,98$ & $10.120 .622,33$ & $1.051 .036,18$ & 0,00 & 0,00 & $14.058 .540,31$ \\
\hline$A C$ & $7.647 .941,68$ & $14.203 .587,24$ & $142.586,47$ & $485.452,54$ & 0,00 & $18.732 .056,32$ \\
\hline AM & $13.397 .670,50$ & $1.900 .199,01$ & $569.238,72$ & 76,11 & 0,00 & $30.204 .839,81$ \\
\hline PA & $3.454 .745,00$ & $13.757 .433,73$ & $360.713,10$ & $337.068,06$ & 0,00 & $32.256 .864,96$ \\
\hline MT & $10.338 .526,09$ & $14.164 .279,39$ & $9.963 .072,12$ & $786.522,71$ & 0,00 & $76.800 .349,24$ \\
\hline
\end{tabular}

Fonte: Elaborado pelos autores, com base nos dados do STN, 2019.Valores atualizados pelo IPCA de 2014.

O estado de Roraima (RORAIMA, 2018) concentrou seus recursos em Demais Subfunçôes e Preservação e Conservação, com aumento em ambas as despesas em cerca de $23,50 \%$ e $14,89 \%$, respectivamente. Houve a redução nos recursos destinados ao Controle Ambiental (1\%) e Recursos Hidricos (0,97\%).

O Amapá (AMAPÁ, 2018) despendeu maiores recursos em Demais Subfunçôes seguido de Preservação Ambiental e Conservação. No período analisado houve o aumento de recursos para a Preservação e Conservação $(2,44 \%)$ e redução nos valores destinados as subfunçóes Controle Ambiental, Recursos Hidricos e Demais Subfunçôes. É preciso salientar o fato de que mesmo a subfunção apresentando os maiores valores na série analisada é preciso considerar sua variação no período estudado, ou seja, ela pode apresentar os maiores valores dentre todas as subfunçôes, mas esses valores podem ser reduzidos ao longo do tempo. 
Tocantins (TOCANTINS, 2018) destinou maiores recursos para as subfunções Preservação e Conservação, seguida de Demais Subfunções. Cabe salientar que no período houve a redução de 0,26\% em Preservação e Conservação e um aumento nas subfunções Controle Ambiental, Recursos Hídricos e Demais Subfunçôes.

O Maranhão (MARANHÃO, 2018) concentrou seus recursos em Preservação e Conservação, seguido de Demais Subfunçôes, onde houve um aumento dessas despesas de $41,09 \%$ e $2,70 \%$, respectivamente. Nesse período ocorreu a redução de $0,58 \%$ na subfunção Recursos Hidricos.

Rondônia (RONDÔNIA, 2018) gastou maiores recursos em Demais Subfunçóes e Controle Ambiental. Entre 2005 e 2015 foi observado o aumento de 0,91\% na Preservação e Conservação e 18,23\% no Controle Ambiental. Em contrapartida, houve a redução de $1 \%$ nas despesas com Recursos Hidricos e $0,74 \%$ nas Demais Subfunçôes.

O Estado do Acre (ACRE, 2018) priorizou as despesas Demais Subfunçôes seguido de Controle Ambiental. Todas as subfunçôes apresentaram uma evolução no período analisado, a exceção de Recuperação de Áreas Degradadas que apresentou uma redução de $0,33 \%$.

No período analisado o Amazonas (AMAZONAS, 2018) encaminhou maiores recursos para a Demais Subfunções seguido de Preservação e Conservação. O estado apresentou uma redução no dispêndio para a subfunção Preservação e Conservação (0,46\%) e para Recursos Hídricos (0,88\%); e crescimento em Demais Subfunçôes (0,23\%) e Controle Ambiental (1,09\%). $\mathrm{Na}$ série analisada o estado declarou recursos na subfunção Recuperação de Areas Degradadas apenas no ano de 2012.

O Pará (PARÁ, 2018) teve maiores despesas em Demais Subfunções seguido de Controle Ambiental, ambas apresentaram crescimento no período analisado de $9,06 \%$ e 3,39\%, respectivamente. Ademais, houve a redução de 0,74\% nos recursos destinados a Preservação e Conservação e uma queda 0,91\% para os Recursos Hidricos.

O Estado do Mato Grosso (MATO GROSSO, 2018) apresentou maiores dispêndios em Demais Subfunçôes, seguido de Controle Ambiental. Nesse período ocorreu o aumento nas subfunçóes Preservação e Conservação (38,87\%) e Recuperação de Áreas Degradadas (67,16\%). Simultaneamente, ocorreu uma queda de $0,35 \%$ nos recursos destinados a subfunção Controle Ambiental.

No período de 2005 a 2015 as subfunções que receberam os maiores recursos foram Demais Subfunções, seguida de Preservação e Conservação Ambiental. É preciso salientar que nesse período esses estados não declararam dispêndio na subfunção Meteorologia. Além disso, os estados de Roraima, 
Amapá, Maranhão e Rondônia não destinaram recursos para a subfunção Recuperação de Áreas degradadas no período analisado.

A respeito da participação da gestão ambiental no orçamento desses estados (razão entre Despesa com gestão ambiental e Despesas Totais) observou- se que essa despesa correspondeu a menos de $1 \%$ dos orçamentos estaduais no período analisado. A participação média dos gastos ambientais no orçamentos dos estados entre 2005 e 2015 correspondeu a: Roraima (0,10\%), Amapá (0,19\%), Tocantins (0,38\%), Maranhão (0,22\%), Rondônia (0,29\%), Acre (0,92\%), Amazonas (0,48\%), Pará (0,63\%) e Mato Grosso (0,71\%).

Os estados da Amazônia Legal que apresentaram maior participação da despesa com gestão ambiental nos orçamentos estaduais foram: Acre, seguido de Mato Grosso e Pará. Foi observado uma evolução na participação da despesa com gestão ambiental nos orçamentos em todos os estados, a exceção do Amapá e do Amazonas, que apresentaram redução no período. Foi possível observar que mesmo havendo o crescimento dos valores destinados a essa despesa no período analisado, seu percentual em relação a despesa total ainda é baixo.

Nesse sentido, a análise da despesa com gestão ambiental no período de 2005 a 2015 mostrou que houve um aumento dos valores destinados a essa despesa em todos os estados, com exceção do Amazonas e do Amapá. No entanto, esse crescimento, quando comparado em termos do orçamento governamental não ultrapassou $1 \%$. Esses resultados corroboram com os encontrados na literatura, que apontam as regiōes Norte e Nordeste como as que menos gastam na área ambiental. Tal afirmação é confirmada pelo relatório divulgado pelo IDESAM em 2017, o qual afirma que os estados da região Norte destinaram em média 0,8 a $0,98 \%$ dos seus orçamentos para a gestão ambiental no período de 2008 a 2015 (IDESAM, 2017; GUANDALINI et al, 2013).

Ao se analisar as subfunçốes, de modo a compreender qual delas foi considerada prioridade dentro da gestão ambiental, observou-se que aquelas que receberam maiores recursos foram Demais Subfunçôes, seguida de Preservação e Conservação Ambiental.

O maior gasto em Preservação e Conservação Ambiental significa que os estados têm destinado mais recursos para defender e conservar os ecossistemas. Quanto ao crescimento na subfunção Demais Subfunçôes - Gestão ambiental, ainda são poucos os estudos voltados a sua análise, por conta disso, pouco se sabe sobre os critérios para alocação de recursos nessa categoria. O que se sabe é que essa subfunção pode ser qualquer despesa que esteja relacionada a gestão ambiental, por exemplo, despesas com Administração geral que são categorizadas nessa subfunção. Além disso, essa subfun- 
ção também contempla novas atribuições da gestão ambiental que ainda não estão expressas na Portaria 42/1999, que define as despesas por função e subfunção (BORINELLI et al, 2017; GUANDALINI et al, 2013).

\section{CONSIDERAÇÕES FINAIS}

A continuidade das políticas públicas ambientais é dependente de recursos públicos governamentais aplicados em gestão ambiental. Esses recursos, sob a forma de despesas com gestão ambiental, são influenciados por fatores ambientais, econômicos e políticos de cada região.

Tais fatores puderam ser verificados no presente trabalho, o qual analisou o comportamento das despesas com gestão ambiental nos anos de 2005 a 2015, observando como os estados aplicaram os recursos na gestão ambiental e a participação dessa despesa nas despesas totais. A partir dos dados obtidos, foi possível observar que dentre os estados analisados aqueles que mais destinaram recursos para a área ambiental foram o Mato Grosso, Pará, Amazonas e Acre. Esse resultado pode estar associado ao aumento de desmatamento em tais estados, o que acarretou em maiores despesas em relação ao combate contra as ações de destruição da floresta. Quanto à participação da despesa

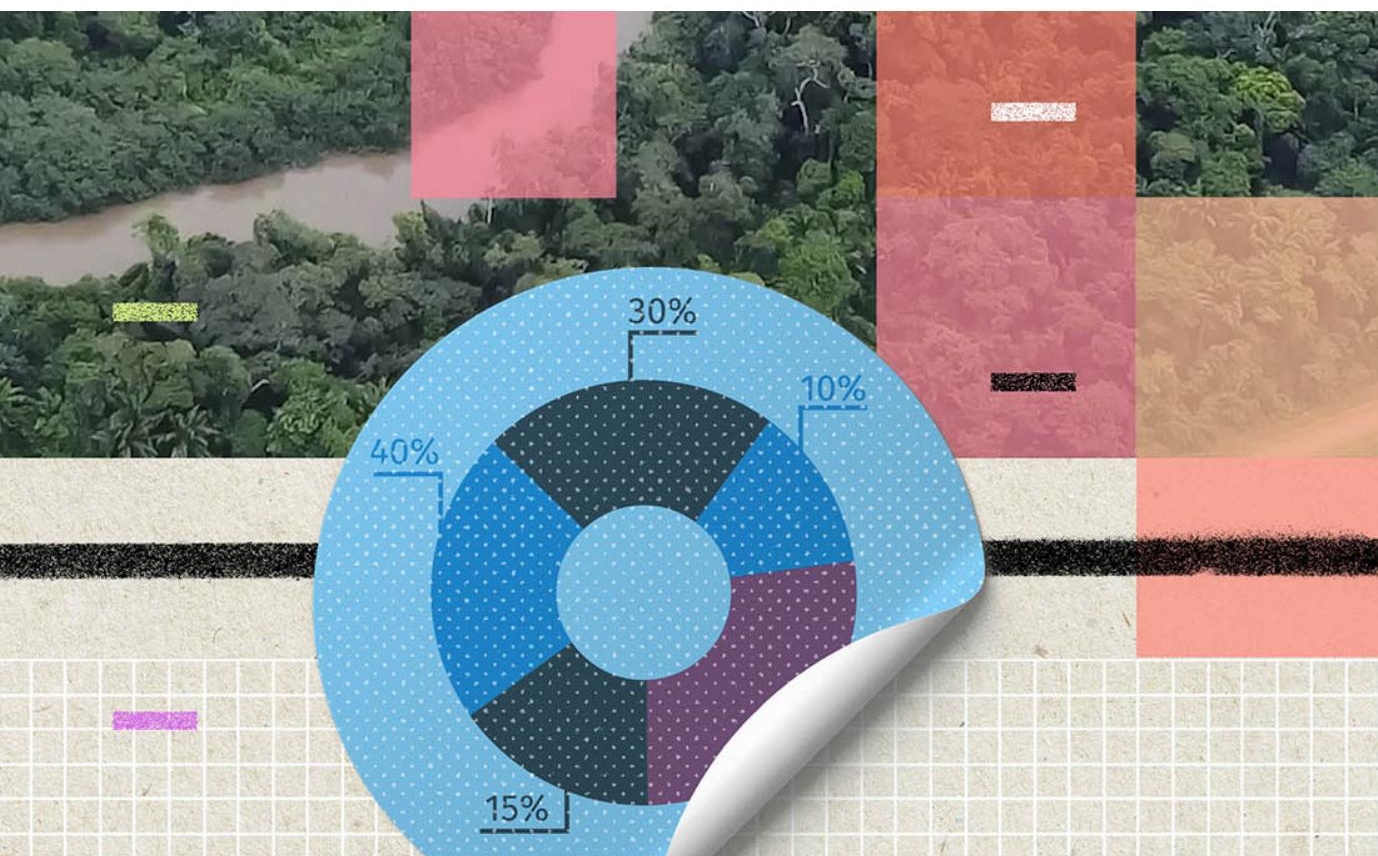


com gestão ambiental nos orçamentos governamentais, observou-se que a gestão ambiental correspondeu a menos de $1 \%$ dos orçamentos dos estados da Amazônia Legal no período analisado.

No caso da despesa com gestão ambiental, foi possível observar que os Estados investem pouco em relação a outros setores, contribuindo no entendimento de que não se configura como um setor prioritário; o que gera preocupação em relação aos problemas ambientais potenciais, decorrentes de baixos gastos em gestão ambiental em suas mais variadas áreas: preservação, conservação, recuperação de áreas degradadas, controle ambiental, entre outros. Além disso, no que tange a atuação dos governos na preservação da Amazônia Brasileira, não é evidente na classificação das despesas se as ações de gestão ambiental são de prevenção ou de remediação. No caso deste estudo foi possível observar que a ação governamental ocorreu após a degradação dos recursos naturais de modo a remediar as consequências advindas da exploração destes.

Tendo em vista que o Brasil possui a maior parte da Amazônia em seu território, urge a necessidade que tal discussão seja constante na pauta ambiental do governo e de seus tomadores de decisão, e que seja tida como prioridade pelos governos em todas as esferas da democracia.

Dentre as limitaçóes encontradas no desenvolvimento desta pesquisa situa-se a própria fonte de dados. A base de dados referente as despesas, mesmo sendo originada de sites oficiais ainda é passível de erro quanto a correta delimitação das despesas no orçamento. A compreensão da despesa pública em todos os setores não é uma tarefa de pouco trabalho. Logo, compreendê-la não é simples e sua descriminação no orçamento é passível de erro por parte daqueles que a declaram.

Ademais, esse estudo sugere como recomendação para pesquisas futuras o desenvolvimento de pesquisas que associem a despesa ambiental com os resultados de análises da preservação de rios e mares, do controle do desmatamento a nível municipal ou estadual. Esse tipo de pesquisa é de suma importância no sentido de fornecer subsídios para elaboração do orçamento ou para a destinação de recursos para a área ambiental.

\section{Notas}

1https://siconfi.tesouro.gov.br/siconfi/pages/public/consulta_finbra/finbra_list.jsf. Acesso: 17 jul. 2021. 2 http://www.turismo.ma.gov.br/amazonia-maranhense/ Acesso: 17 jul. 2021. 


\section{Referencias}

ACRE. Portal da transparência do governo do Acre. Disponível em: https://bit.ly/3i1B62q. Acesso em: 27 nov. 2018.

AGENCIA SENADO. LRF. Disponível em: https://bit.ly/3yob2tP. Acesso em: 18 ago. 2020.

ALMEIDA, M.; GIAMBIAGI, F. \& PESSOA, S.( 2006) Expansão e dilemas no controle do gasto público federal. Boletim de Conjuntutra, n.73, p. 89-98.

AMAPÁ. Portal da transparência do governo do Amapá. Disponível em: https://bit. ly/3BwzV2t /. Acessado em: 27 nov. 2018.

AMARANTE, P. \& MOREIRA, I.T. A evolução dos gastos públicos por função e por grupo de despesas no período de 1980-2006. In: ENCONTRO DE INICIAÇÃO A DOCÊNCIA, 12p., 2009, Paraíba. Anais do XII Encontro de Iniciação a docência. Paraíba: Universidade Federal da Paraíba.

AMAZONAS. Portal da transparência do governo do Amazonas. Disponível em: https://bit.ly/3BwzV2t. Acessado em: 27 nov. 2018.

AMAPA. Portal da transparência do governo do Amapá. Disponível em: https://bit. ly/3BwzV2t. Acesso em: 27 nov. 2018.

BAQUERO, F. S., ROCHA, J. S. \& ÓRTEGA. J. (2006). Desarrollo rural en los países de América Latina y el Caribe: el rol de las políticas Públicas, In: Políticas Públicas Y Desarrollo en América Latina y el Caribe: el papel del gasto público ( $1^{\mathrm{a}}$ ed.), Santiago do Chile.

BORINELLI, B.; BACCARO, T. A. \& GUANDALINI, N. N. (2017). Os gatos ambientais dos estados brasileiros: uma análise exploratória. Revista do Serviço Público, v. 68, n. 4, pp. 807-834.

BRASIL. Constituição da República Federativa do Brasil de 1988. Brasília, DF: Presidência da República, [2019]. Disponível em: https:// bit.ly/3eNA9IV. Acesso em: 11 mai. 2017.

BRASIL. Lei complementar $n^{\circ} 101$, de 4 de maio de 2000. Brasília, 2000. Disponível em: https://bit.ly/3zuV5MM. Acesso em: 11 de maio de 2019.
BRASIL. Lei complementar $n^{\circ} 140$, de 8 de dezembro de 2011, de 31 de agosto de 1981. Brasília, 2011. Disponível em: https://bit. ly/3eNYA9a. Acesso em: 11 de maio de 2019.

BRASIL. Ministério do Planejamento, Orçamento e Gestão. Secretaria de Orçamento Federal. Manual técnico de orçamento MTO. Brasília, 2017.

BRASIL. Ministério da Economia. Execução Orçamentária e Financeira. Disponivel em: https://bit.ly/3rt7opU. Acesso em: 20 ago. 2020.

BESKOW, E. \& MATTEI, L. Notas sobre a trajetória da questão ambiental e principais sistemas em debate na conferência Rio + 20 . Revista NECAT, v. 1, n. 2, pp. 4-12.2012

BUENO, W.; OLIANA, F. \&BORINELLI, B.(2013). O Estudo do Gasto Público em Meio Ambiente. Economia \& Região, v. 1, n. 1, p. 118-133.

CFC. ITG 2004 - Interação da Entidade Com o Meio Ambiente: Normas Brasileiras de Contabilidade. Brasília: CFC, 2013. Disponivel em: https://bit.ly/3y4PCMf. Acesso em: 15 ago. 2020.

COTA, R.T.C. Uma imersão nas contas públicas brasileiras. Texto para discussão. IPEA: Brasília, 2017.

DANTAS, M. K. et al. Análise dos gastos públicos com gestão ambiental no Brasil. Revista de Gestao Social e Ambiental, v. 8, n. 3, p. 3-17, 2014.

FERRAZ, F. C. Crise financeira global: impactos na economia brasileira, política econômica e resultados. Dissertação de mestrado em Economia. Universidade Federal do Rio de Janeiro, 2013. 104f.

GALLASSI, Juliana N. et al. Gastos públicos ambientais: um estudo das mesorregiões do estado do Paraná. In: Encontro Internacional sobre Gestão Empresarial e Meio Ambiente, 19,. São Paulo, 2017. Anais do XIX ENGEMA. São Paulo: São Paulo, 2017. 
GALINATO, G. \& GALINATO, S. The effects of government spending on deforestation due to agricultural land expansion and $\mathrm{CO}_{2}$ related emissions. Ecological Economics, v. 122, p. 43-53, 2016.

GERHARDT, T. E. \& SILVEIRA, D.T. Métodos de pesquisa. 1 .ed. Porto Alegre: Editora da UFRGS, 2009.

GREMAUD, A. P.; VASCONCELLOS, M. A. S. \& JÚNIOR R. T. Economia Brasileira Contemporânea. 6. ed. São Paulo: Atlas, 2007.

GRUDTNER, V. \& ARAGON, E. K.S.B. Multiplicador dos gastos do governo em períodos de expansão e recessão: evidências empíricas para o Brasil. Revista Brasileira de Economia, v. 71, n. 3, pp. 321-345, 2017.

HAYASHI, C.; SILVA, L.H.A. (2015) Instrumentos de Políticas Públicas em Gestão Ambiental e Sustentabilidade no Brasil. XI Fórum Ambiental da Alta Paulista, v. 11, n. 7, pp. 37-51.

IBGE. Instituto Brasileiro de Geografia e Estatística. 2019. Disponível em: https://bit. ly/3rtd6s3. Acesso em: 17 mai. 2019.

JUNIOR, N. L. S. A conexão entre crise econômica e crise ambiental no Brasil. IPEA. Boletim regional, urbano e ambiental, n. 13, jan.-jun. 2016.

LIMA, G. F. C. A institucionalização das políticas e da gestão ambiental no Brasil: avanços, obstáculos e contradições. Desenvolvimento e Meio Ambiente, v. 23, pp. 121-132, 2011.

LIMA, T. D. \& DEUS, L. N. A crise de 2008 e seus efeitos na economia brasileira. Revista Cadernos de Economia, Chapecó, v. 17, n. 32, pp. 52-65, 2013.

MARANHÃO. Portal da transparência do governo do Maranhão. Disponível em: https://bit.ly/3yodtgd. Acesso em: 27 nov. 2018.

MARCONI, M. A. \& LAKATOS, E. M. Fundamentos de metodologia científica. 5 ed. São Paulo: Atlas, 2003.
MATO GROSSO. Portal da transparência do governo do Mato Grosso. Disponível em: https://bit.ly/2UFHSSu. Acesso em: 27 nov. 2020.

MMA. Ministério do Meio Ambiente. Receitas e Despesas. Disponivel em: https://www. mma.gov.br/despesas.html. Acessado em: 18 ago. 2020.

MMA. Ministério do Meio Ambiente. 2019. Disponível em: https://bit.ly/2TtHEo4. Acesso em: 17 mai. 2020.

MMA. Plano de Ação para Prevenção e Controle do Desmatamento na Amazônia Legal (PPCDAm). Dispinível em: https://bit.ly/3eJLOsf. Acesso em: 22 ago. 2020.

MOURA, A. M. M. et al. Gastos ambientais no Brasil: proposta metodológica para aplicação no orçamento federal. Texto para discussão, Instituto de Pesquisa Econômica. Aplicada. - Brasília - Rio de Janeiro: Ipea, 2017.

PARÁ. Portal da transparência do governo do Pará. Disponível em: https://bit. ly/36T3LAl. Acesso em: 27 nov. 2020.

PROJETO Prodes Digital. Mapeamento do desmatamento da Amazônia com Imagens de Satélite. São José dos Campos: Instituto Nacional de Pesquisas Espaciais. Disponível em: https://bit.ly/36Vlx5V. Acesso em: 08 out. 2017.

REIS, L. G. R. \& OLIANA, F. H. Uma análise sobre o comportamento dos gastos públicos em gestão ambiental na cidade de Londrina-PR. In: Congresso Brasileiro de Custos, 21., 2014, Rio Grande do Norte, Anais do XXI Congresso Brasileiro de Custos. Natal.

RIBEIRO, M. d. S. Contabilidade ambiental. 2. ed. São Paulo: Editora Saraiva, 2010.

RONDÔNIA. Portal da transparência do governo do Rondônia. Disponível em: https:// bit.ly/3xaGnZT. Acesso em: 27 nov. 2020.

RORAIMA. Portal da transparência do governo de Roraima. Disponível em: https:/l bit.ly/3y4NJz9. Acesso em: 27 nov. 2020. 
ROSA, G. R.; FABRE, V. V. \& DALLABONA, L. F.(2018) Gastos ambientais nos municípios catarinenses: o que mudou após os desastres naturais ocorridos nos últimos anos? Revista Livre de Sustentabilidade e Empreendedorismo, v. 3, n. 4, pp. 24-50.

TOCANTINS. Portal da transparência do governo do Tocantins. Disponível em: http:// www.transparencia.to.gov.br/\#!o_portal. Acessado em: 27 nov. 2020.

TCU - TRIBUNAL DE CONTAS DA UNIÃO. Visão geral sobre a Função Gestão Ambiental. Relatório de levantamento. Brasília: 2014.
VASCONCELLOS, M. A. S. \& GARCIA, M. E. Fundamentos de Economia. 4.ed. São Paulo: Saraiva, 2008.

YOUNG, C. E. F. Mecanismos de financiamento para a conservação no Brasil. Conservação Internacional no Brasil, [S. I.: s.n.], p. 1- 8, 2005. ZHANG, Quianxue et al. (2017). Does government expenditure affect environmental quality? Empirical evidence using Chinese city-level data. Journal of Cleaner Production, v. 161, pp. 143-152, 2017.

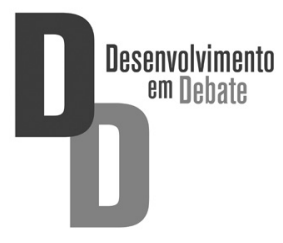

